\title{
A Case Report of Chondromyxoid Fibroma of the Neck of Femur, Intracapsular Location
}

\author{
Siddharth Jain ${ }^{1}$, Sitender Garg ${ }^{1}$, Ravi Mittal ${ }^{1}$ \\ Learning Point of the Article: \\ Always keep your criteria broad for diagnosis, whenever you are dealing with a case of tumour.
}

\section{Abstract}

Introduction: Chondromyxoid fibroma (CMF) is an uncommon benign tumor accounts for $<2 \%$ of all benign and $<1 \%$ all bone tumors. It is a cartilage tumor with myxoid and fibrous elements. Because of rarity and resemblance with other benign and malignant tumor, diagnosis of this tumor always remains challenging. Often, this lesion affects metaphysis of long growing bones of children and young adults. Common locations of this tumor are around the growth plate of proximal tibia and fibula and distal femur.

Case Report: A 21-year-old male presented to orthopedic outpatient department with a history of the left hip pain for 1 year, following a trivial fall before 1 year. The patient was not able to do heavy strenuous activities such as running, jumping, and other sports activities. Terminal range of movements were painful. Magnetic resonance imaging suggested of cystic lesion involving synovial lining near head-and-neck junction of the left femur. Curettage of the lesion was done. The bone defect was not found to be large enough to be filled with bone graft. Histopathological examination showed lobular pattern with stellate to spindle-shaped cells on the myxoid background.

Conclusion: CMF of subcapital region of femoral neck is an extremely unusual presentation. When occurring in middle-aged persons and in uncommon locations, this can raise suspicion of chondrosarcoma. Although intralesional curettage has the risk of recurrence in post-operative period, sufficient and careful curettage and excision of lesion will be enough to treat these benign lesions with good prognosis.

Keywords: Chondromyxoid fibroma, intracapsular, benign tumor.

\section{Introduction}

Chondromyxoid fibroma (CMF) is an uncommon benign tumor. Overall, it represents for $<2 \%$ of all benign and $<1 \%$ all bone tumors $[1,2]$. It is a cartilage tumor with myxoid and fibrous elements. Its incidence is very less. Because of rarity and resemblance with other benign and malignant tumor, diagnosis of this tumor always remains challenging. Often, this lesion affects metaphysis of long growing bones of children and young adults [3]. Common locations of this tumor are around the growth plate of proximal tibia and fibula and distal femur [4]. Recurrence after treatment is common and varies from $20 \%$ to $80 \%$, recurrence mostly remain benign $[5,6]$. We present 21 year-old male with an unusual presentation of CMF of neck of femur with no involvement of head. As per best of our knowledge, we did not found any reported case of CMF of subcapital region of neck of femur in previous literature.

\section{Case Report}

A 21-year-old male presented to orthopedic outpatient department with a history of the left hip pain for 1 year, following a trivial fall before 1 year. The patient was not able to do heavy strenuous activities such as running, jumping, and other sports activities. Terminal range of movements were painful. FABER test was positive. The patient was able to raise his leg actively. Radiograph left hip revealed a radiolucent swelling along inferior part of neck with a well-defined,

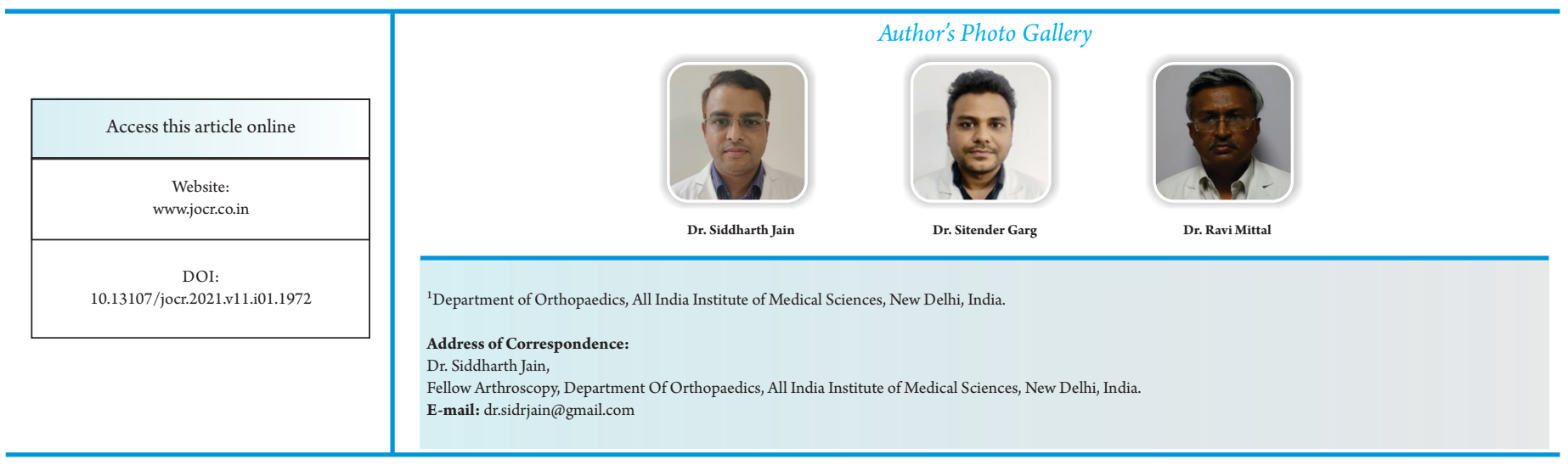

Journal of Orthopaedic Case Reports | pISSN 2250-0685 | eISSN 2321-3817 | Available on www.jocr.co.in | doi:10.13107/jocr.2021.v11.i01.1972 This is an Open Access article distributed under the terms of the Creative Commons Attribution Non-Commercial License (http://creativecommons.org/licenses/by-nc/3.0) which permits unrestricted non-commercial use, distribution, and reproduction in any medium, provided the original work is properly cited. 


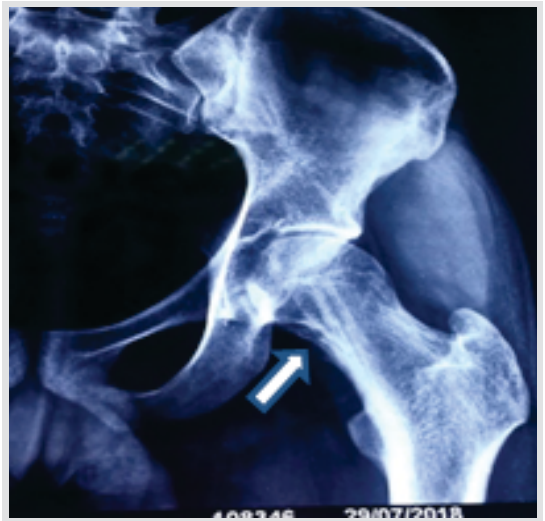

Figure 1: Radiograph (arrow) showing oval-shaped lesion without any calcification or periosteal reaction.

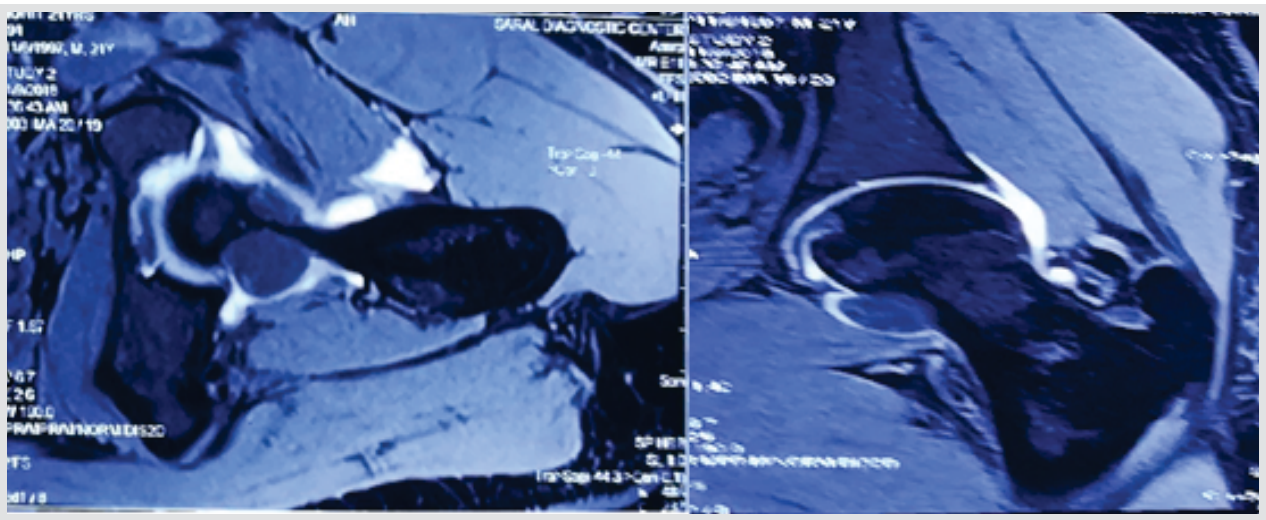

Figure 2: $(\mathrm{a}$ and b) Magnetic resonance imaging showing cystic lesion involving synovial lining near head-and-neckjunction of the left femur. eccentric osteolytic lesion involving subcapital region of the left femoral neck. The lesion was oval shaped and without any calcification or periosteal reaction (Fig. 1).

Magnetic resonance imaging (MRI) suggested of cystic lesion involving synovial lining near head-and-neck junction of the left femur (Fig. 2a and b).

Under regional anesthesia, with patient in supine position, the lesion was approached through smith and Peterson approach to the left hip. After cutting the left hip capsule in T shape and pulling the hip in flexion abduction and external rotation, the lesion was found. It contained rubbery and gelatinous material along synovial lining of inferomedial capsule with slight erosion of inferior neck. Curettage of the lesion was done. The bone defect was not found to be large enough to be filled with bone graft. Histopathological examination showed lobular pattern with stellate to spindle-shaped cells on the myxoid background (Fig. 3). Few osteoclast type of giant cells were found in the periphery of the lobules. Tumor cells had oval- to spindleshaped nucleus with surrounding densely eosinophilic cytoplasm within a myxoid background. It was consisted with fibromyxoid chondroma.

In post-operative period, isometric quadriceps exercises were started on the same day of surgery. Knee and ankle range of

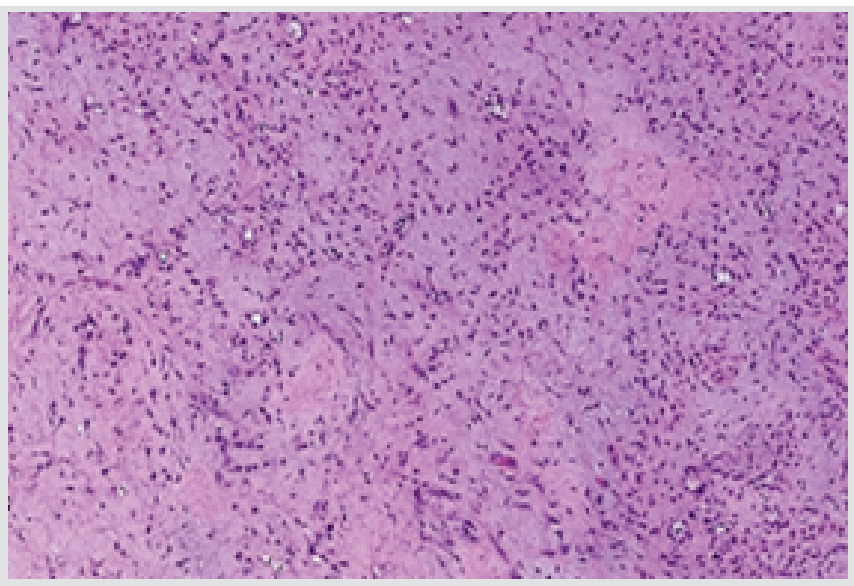

Figure 3: Microscopic picture showing lobular pattern with stellate to spindle-shaped cells on the myxoid background. movement exercises were started since the next day of surgery. He was discharged after 2 days with non-weight-bearing walking with walker support. He was followed at 4 weeks, 8 weeks, and 3 months. The patient was allowed on full weightbearing from 2 months. He has a painless gait with no complications or recurrence till date.

\section{Discussion}

CMF is one of the rare benign tumors of bone. Jaffe and Lichtenstein have described 1st time in 1948. Despite its name, CMF is by nature a tumor of predominantly chondroid cells and originate from physeal cartilage plate [5]. It occurs commonly in the second and third decades of life [3]. It has a slight male preponderance.

CMF can occur in any osseous site. Often, it involves metaphyseal region of the long bones near to growth plate [4]. The proximal tibia is the most common site of involvement in all large reported series. This site was followed by the ilium, the ribs, the distal femur, the metatarsals, and the lower tibia, proximal fibula and distal femur, rarely does it involve flat bones and small tubular bone $[7,8]$.

Some patients can be asymptomatic but most of the patients presents with a mild pain with local tenderness, decrease range of movement of adjacent joint $[9,10]$. Approximately 5\% of cases, it presents with pathological fracture. Radiologically, it normally appears as lobulated or oval eccentric lytic lesion with well-defined sclerotic margins. It is often expensile without any periosteal reaction. Pseudotrabeculation or septation may be present [4]. CT scan can help to identify any breach in cortical integrity and intralesional calcifications [11]. MRI features are often non-specific lesion appeared as decreased signal intensity on T1-weighted images and increased signal intensity on T2weighted images [11].

Diagnosis of CMF depends on the characteristics histological appearance. These consist of lobular pattern with stellate or 
spindle-shaped cells in a myxoid or chondroid background. Lobules demonstrate hypocellular centers and hypercellular peripheries. Multiple giant cells are often present at the lobular peripheries $[3,4]$. Giant cell at the periphery of the chondroid lobules with plump hyperchromatic nuclei is characteristic of CMF [2]. Similar histologic feature were seen in our case.

Differential diagnosis of CMF includes chondrosarcoma, chondroblastoma, aneurysmal bone cyst, and enchondroma but the characteristic histological features ruled out these lesions. In a recent study, it was found that CMF of the femur cannot be differentiated from chondrosarcoma by $18 \mathrm{~F}$ fluorodeoxyglucose-positron emission tomography positron emission tomography/computed tomography, and histopathology is still the best diagnostic tool [12].

Open incisional biopsy is preferred. Intralesional curettage with or without bone grafting is preferred technique for treatment. Many studies favor en block excision as preferred technique to prevent recurrence [13].

In presented case, adequate intralesional curettage was done without bone grafting. As per best of our knowledge, we did not found any reported case of CMF of subcapital intracapsular region of neck of femur in previous literature.

\section{Conclusion}

CMF of subcapital region of femoral neck is an extremely unusual presentation. When occurring in middle-aged persons and in uncommon locations, this can raise suspicion of chondrosarcoma. Although intralesional curettage has the risk of recurrence in post-operative period, sufficient and careful curettage and excision of lesion will be enough to treat these benign lesions with good prognosis.

\section{Clinical Message}

CMF of subcapital region of femoral neck is a rare pathological condition. High degree of suspicion will be required. This can be treated successfully with open curettage.

\section{References}

1. Campanacci M. Chondromyxoid fibroma. In: Campanacci M, editor. Bone and Soft Tissue Sarcomas. New York: Springer; 1999.p. 265-78.

2. Dahlin DC. Chondromyxoid fibroma of bone, with emphasis on its morphological relationship to benign chondroblastoma. Cancer 1956;9:195-203.

3. Takenaga RK, Frassica FJ, McCarthy EF. Subperiosteal chondromyxoid fibroma: A report of two cases. Iowa OrthopJ 2007;27:104-7.

4. Fletcher CD, Unni KK, Mertens F. Pathology and Genetics of Tumours of Soft Tissue and Bone. Lyon, France: WHO Classification of Tumors; 2002.p. 243-5.

5. Jaffe H, Lichtenstein L. Chondromyxoid fibroma of bone; a distinctive benign tumor likely to be mistaken especially for chondrosarcoma. Arch Pathol (Chic) 1948;45:541-51.

6. Rahimi A, Beabout JW, Ivins JC, Dahlin DC. Chondromyxoid fibroma: A clinicopathologic study of 76 cases. Cancer 1972;30:726-36.

7. Gherlinzoni F, Rock M, Picci P. Chondromyxoid fibroma. The experience at the Istituto Ortopedico Rizzoli. J Bone Joint Surg AM 1983;65:198-204.

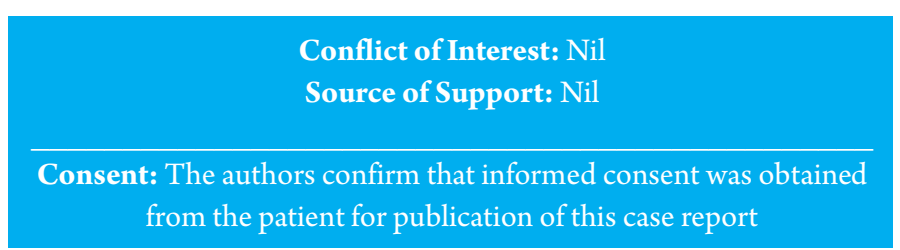

8. Schajowicz F, Gallardo H. Chondromyxoid fibroma (fibromyxoid chondroma) of bone. A clinico-pathological study of thirty-two cases. J Bone Joint Surg Br 1971;53:198-216.

9. Zillmer DA, Dorfman HD. Chondromyxoid fibroma of bone: Thirty-six cases with clinicopathologic correlation. Hum Pathol 1989;20:952-64.

10. Declerck GM, Rawlings ID, Hunt AC. Chondromyxoid fibroma in the metacarpal bone of the thumb. Acta Orthop Belg 1992;58:216-20.

11. Giudici MA, Moser RP Jr., Kransdorf MJ. Cartilaginous bone tumors. Radiol Clin North Am 1993;31:237-9.

12. Okada T, Futani H, Kanto R, Kumanishi S, Tsukamoto Y, Yoshiya S. Chondromyxoid fibroma of the femur can not be differentiated from chondrosarcoma by $18 \mathrm{~F}-\mathrm{FDG}$ $\mathrm{PET} / \mathrm{CT}$, and histopathology is still the final diagnostic tool.J Clin Case Rep 2015;5:661.

13. Bhamra JS, Al-Khateeb H, Dhinsa BS, Gikas PD, Tirabosco $\mathrm{R}$, Pollock RC, et al. Chondromyxoid fibroma management: A single institution experience of 22 cases. World J Surg Oncol 2014;12:283.

\section{How to Cite this Article}

Jain S, Garg S, Mittal R. A Case Report of Chondromyxoid Fibroma of the Neck of Femur, Intracapsular Location. Journal of Orthopaedic Case Reports 2021 January; 11(1):79-81 